\title{
Electron Microscopic Mapping of Deletions on a Streptococcal Plasmid Carrying Extraordinarily Long Inverted Repeats
}

\author{
Detlev Behnke, ${ }^{1}$ Paul K. Tomich, ${ }^{2}$ and Don B. Clewell. \\ Dental Research Institute, Departments of Oral Biology and Microbiology, Schools of Dentistry and Medicine, \\ The University of Michigan, Ann Arbor, Michigan 48109
}

Received April 2, 1980

\begin{abstract}
Deletions $\Delta 101, \Delta 102$, and $\Delta 103$ which occurred within the extraordinarily long inverted repeats of the self-ligated large EcoRI fragment of the streptococcal MLS (macrolides, lincosamides, streptogramin B)-resistance plasmid pSM19035 led to the formation of plasmids pDB101, pDB102, and pDB103. Their molecular lengths were determined by contour length measurements to be $17.8,17.4$, and $13.9 \mathrm{~kb}$, respectively. Electron microscopic examination of self-annealed molecules revealed stem-loop structures with inverted repeats comprising 41 to $91 \%$ of the mass of plasmids. Two unique sequences (US $\mathrm{U}_{1}$ and $\mathrm{US}_{2}$ ) separated the inverted repeats in the case of pDB101 and pDB103, while in pDB102 the repeats were joined at one end and separated at the other by a unique sequence $\left(U S_{2}\right)$. The size of the unique sequence $\mathrm{US}_{2}$ was identical for all three plasmids, and the location of the resistance determinant was determined by electron microscopic examination of selfannealed molecules of the recombinant plasmid pDB201. Mapping of the deletion termini, accomplished by combining electron microscopic and HindIII restriction data, suggested that deletions may occur at preferential sites.
\end{abstract}

The 18-Mdal ${ }^{3}$ streptococcal plasmid pSM19035 (Behnke et al., 1979a) specifies inducible resistance to macrolides, lincosamides, and streptogramin B-type antibiotics (MLS) (Malke, 1974). It has been shown by restriction enzyme analyses (Behnke et al., 1979a) and electron microscopy (Boitsov et al., 1979) that the plasmid has extraordinarily long inverted repeat sequences that comprise about $80 \%$ of the molecule. These sequences are separated by two nonrepeated segments equivalent to 14 and $5 \%$ of the pSM19035 genome. Cleavage of pSM19035 with EcoRI gave rise to two fragments of about 14 and 4 Mdal; with HindIII, 15 fragments were obtained, 12 of which represented six pairs of identical

\footnotetext{
1 Present address: Academy of Sciences of the GDR, Central Institute of Microbiology and Experimental Therapy, DDR-69 Jena, PSF 73, German Democratic Republic.

${ }^{2}$ Present address: The Upjohn Company, Kalamazoo, Mich. 49001.

${ }^{3}$ Abbreviations used: Mdal, megadalton; MLS, macrolides, lincosamides, and streptogramin B-type antibiotics; $\mathrm{kb}$, kilobase.
}

fragments derived from the inverted repeats (Behnke et al., 1979a). In order to construct a potential streptococcal vector plasmid featuring a single Eco RI cleavage site, the purified large EcoRI fragment of pSM19035 was self-ligated and afterward introduced into the Challis strain of Streptococcus sanguis by transformation (Behnke et al., 1979b). Subsequent analyses of plasmid DNA isolated from three such transformants revealed that the ligated fragment had suffered deletions of various extents, as a result of sequence rearrangements during or following the transformation process. As a result of deletions designated $\Delta 101, \Delta 102$, and $\Delta 103$, three smaller plasmids were obtained. Only one of these plasmids, pDB 101, retained the single $E$ co $R I$ cleavage site while the other two pDB102 and pDB103, were devoid of this site. HindIII analyses of the deletions of the three plasmids, together with HindIII cleavage patterns of the purified EcoRI fragments of pSM19035, allowed the construction of Eco RI/HindIII restriction site maps for $\mathrm{pSM}$ - 

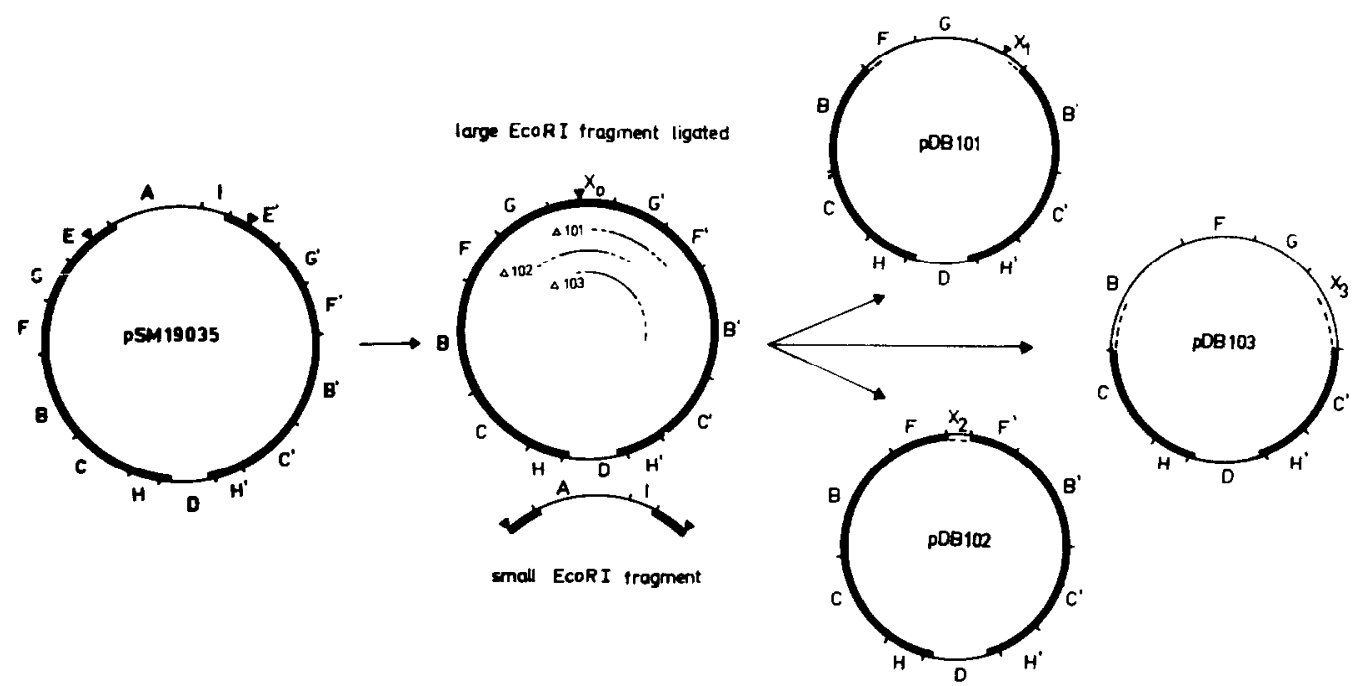

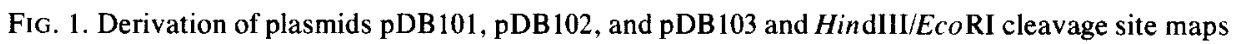
of the plasmids involved. Inverted repeats are indicated by heavy lines; their extension into the terminal HindIII fragments are marked by dotted lines. Light lines represent unique sequences. Arrows label the positions of EcoRI cleavage sites while the letters refer to HindIII fragments. Within the self-ligated large EcoRI fragment, the extent of deletions $\Delta 101, \Delta 102$, and $\Delta 103$ leading to the formation of the respective plasmids are indicated.

19035 and its derivative plasmids (Behnke et al., 1979b; Behnke and Ferretti, 1980a). The results are summarized in Fig. 1. The deletions included portions of one or both of the repeated sequences, and all of them overlap. (No difference in either the type or level of MLS resistance was detectable in the case of the molecules with deletions).
In this paper we report on electron microscopic analyses of the deletion-containing molecules, and combine the data with restriction enzyme analyses to map precisely the boundaries of the deletions. The data suggest that the deletions may involve preferential sites on the plasmid. In addition, the MLS resistance determinant was

TABLE 1

Streptococcal Strains Used as Sources for Plasmid DNa

\begin{tabular}{|c|c|c|}
\hline Strain & Description of the plasmid & Reference \\
\hline Challis (pDB101) & $\begin{array}{l}\text { pDB101, a deletion mutant of the } \\
\text { MLS-resistance plasmid pSM19035 }\end{array}$ & $\begin{array}{l}\text { Behnke et al., 1979b; } \\
\text { Behnke and Ferretti, 1980a }\end{array}$ \\
\hline Challis (pDB102) & $\begin{array}{l}\text { pDB102, a deletion mutant of the } \\
\text { MLS-resistance plasmid pSM19035 }\end{array}$ & Behnke et al., $1979 b$ \\
\hline Challis (pDB103) & $\begin{array}{l}\text { pDB103, a deletion mutant of the } \\
\text { MLS-resistance plasmid pSM } 19035\end{array}$ & Behnke et al., 1979b \\
\hline Challis (pDB201) & $\begin{array}{l}\text { pDB201, a recombinant plasmid } \\
\text { between pVA318 and the MLS- } \\
\text { resistance determinant of pDB102 }\end{array}$ & Behnke and Ferretti, 1980b \\
\hline V318 & $\begin{array}{l}\text { pVA318, a 5.4-kb cryptic plasmid } \\
\text { having a single HindIII restriction site }\end{array}$ & Macrina and Scott, 1978 \\
\hline
\end{tabular}


observed to be located on one of the unique sequences of pSM19035.

\section{MATERIALS AND METHODS}

Bacteria. All bacterial strains which served as sources for the isolation of plasmid DNA are listed in Table 1. The Streptococcus mutans strain V318 was kindly provided by F. Macrina. Brain heart infusion broth from Difco was used to grow all strains.

Isolation of plasmid DNA. Growth in the presence of DL-threonine (Chassy, 1976) or glycine (Reider and Macrina, 1976) facilitated lysis of $S$. sanguis or $S$. mutans; respectively. Deproteinized cleared lysates were subjected to dye-buoyant density gradient centrifugation to isolate and purify plasmid DNA (Behnke and Ferretti, 1980a). All plasmid DNAs were kept at $4^{\circ} \mathrm{C}$ in 10 $\mathrm{mM}$ Tris- $\mathrm{HCl}$ (pH 7.4).

Electron microscopy. The techniques used for electron microscopy of native and self-annealed plasmid molecules were as described elsewhere (Davis et al., 1971; Sharp et al., 1972; Yagi and Clewell, 1976). An Hitachi HS-8 electron microscope was used throughout these experiments. Bacteriophage $\phi$ X174 RFII DNA $(5.386 \mathrm{~kb})$ (Sanger et al., 1977) served as a molecular length standard for both double- and singlestranded DNA. For the latter $\phi X 174$ RFII DNA was subjected to the same denatura- tion-renaturation procedure as the plasmid DNAs. All measurements were made after projection on a Nikon profile projector (Model 60).

\section{RESULTS}

Molecular Length of Native Plasmids and Their Different Regions after

Self-Annealing of Denatured Molecules

The molecular length of native plasmid DNA was determined by contour length measurement of open circular molecules [generated by heating at $95^{\circ} \mathrm{C}$ for $10 \mathrm{~min}$ in buffer (Yagi and Clewell, 1976)] to be 17.9 $\mathrm{kb}$ for $\mathrm{pDB} 101,17.4 \mathrm{~kb}$ for $\mathrm{pDB} 102$, and $14.0 \mathrm{~kb}$ for $\mathrm{pDB} 103$ (Table 2). These results corresponded to molecular lengths of 17.8 , 16.9 , and $14.5 \mathrm{~kb}$ for the respective plasmids, as calculated from restriction enzyme analyses (Behnke et al., 1979b). The slight discrepancies between the two values for pDB102 and pDB103) are within experimental error.

Denaturation of open circular plasmid molecules followed by a short renaturation period allowed the formation of intrastrand duplex regions as a result of reannealing of inverted repeat sequences. As expected from restriction data stem-loop structures were observed for all three plasmids indicating the presence of inverted repeat se-

TABLE 2

Molecular Length of Native Plasmids and Their Different Regions after Denaturation AND INTRASTRAND ANNEALING ${ }^{a}$

\begin{tabular}{lccccc}
\hline & & & \multicolumn{2}{c}{ Self-annealed molecules } & \\
\cline { 3 - 5 } Plasmid & $\begin{array}{c}\text { Molecular length of } \\
\text { native molecules }\end{array}$ & US $_{1}$ & US $_{2}$ & IR & Total \\
\hline pDB101 & $17850 \pm 890(10)^{b}$ & $3050 \pm 270$ & $1440 \pm 200$ & $6870 \pm 530$ & $18230 \pm 1530(9)^{b}$ \\
pDB102 & $17400 \pm 540(10)$ & - & $1460 \pm 170$ & $7760 \pm 560$ & $16980 \pm 1290(12)$ \\
pDB103 & $13950 \pm 1020(8)$ & $6320 \pm 560$ & $1310 \pm 180$ & $3420 \pm 390$ & $14470 \pm 1520(6)$ \\
pDB201 & $7160 \pm 570(6)$ & $5280 \pm 240$ & $1530 \pm 180$ & $240 \pm 30$ & $7290 \pm 480(12)$ \\
\hline
\end{tabular}

${ }^{a}$ The molecular lengths are given in nucleotides or nucleotide pairs (bp). US, unique sequences; IR, inverted repeat.

${ }^{b}$ The figures in parentheses refer to the number of molecules measured. 

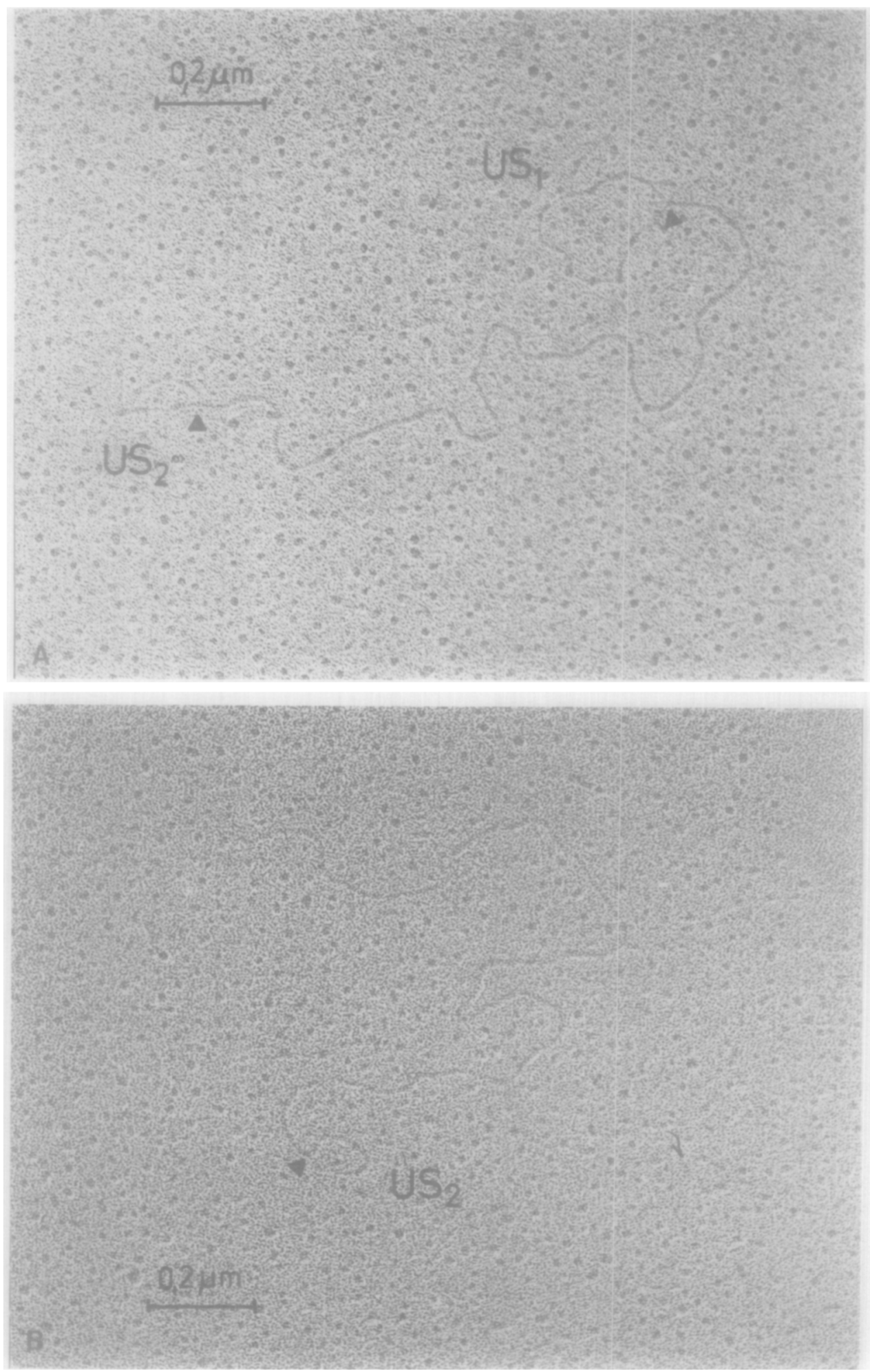

FIG. 2. Electron micrographs of denatured and self-annealed plasmid molecules. Junction points between double-stranded regions and single-stranded loops are marked by arrows. (A) pDB101; (B) pDB 102; (C) pDB 103; (D) pDB201. 

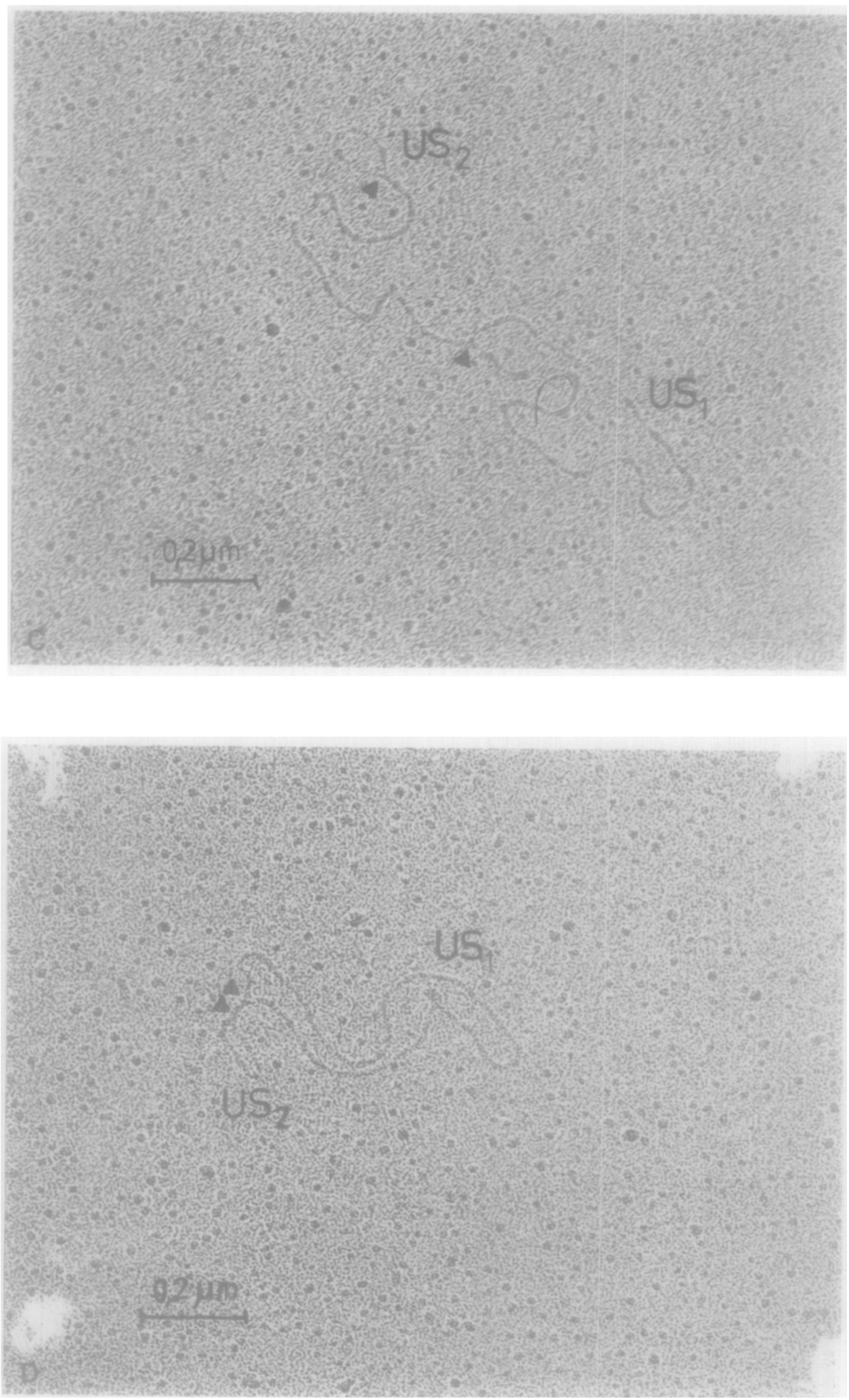

FIG. 2-Continued. 
quences of different lengths for pDB101, pDB102, and pDB103. Electron micrographs of typical molecules are shown in Figs. 2A-C. In self-annealed molecules of plasmids $\mathrm{pDB} 101$ and $\mathrm{pDB} 103$ singlestranded loops were observed on both ends of the continuous central double-stranded region (Figs. $2 \mathrm{~A}$ and $\mathrm{C}$ ), thus indicating the presence of two interstitial unique sequences ( $\mathrm{US}_{1}$ and $\mathrm{US}_{2}$ ) that separate the inverted repeat stretches in these plasmids. In contrast, only one terminal single-stranded DNA loop was detectable in self-annealed molecules of pDB102 (Fig. 2B). Plasmid pDB102, therefore, consisted of two inverted repeats which were connected with each other at one end and separated at the other by a short intervening sequence $\left(\mathrm{US}_{2}\right)$. (A second interstitial sequence shorter than 50-75 base pairs may have escaped detection by electron microscopic techniques.)

The molecular length of inverted repeats and nonrepeated sequences were determined by measuring the different regions of denatured and self-annealed plasmid molecules (Table 2). Plasmid pDB103 was the result of the largest deletion $(\Delta 103)$ reducing the inverted repeat regions to only $47 \%$ of the plasmid genome and generating a large unique sequence $\left(\mathrm{US}_{1}\right.$ ) that comprised $44 \%$ of the molecule. The symmetrical deletion $\Delta 102$ led to the formation of pDB 102 which had an extreme of more than $91 \%$ of duplicated DNA in its genome. Relations of inverted repeat to nonrepeated sequences of pDB 101 were similar to those observed for the parental plasmid pSM19035. For all three plasmids the smaller of the two unique sequences (US $\mathrm{U}_{2}$ ) was similar in size, averaging a length of $1.4 \mathrm{~kb}$ (Table 2). This value was consistent with the one determined previously for $\mathrm{US}_{2}$ in selfannealed pSM19035 molecules (Boitsov et al., 1979).

\section{Localization of the Resistance}

Determinant on $U S_{2}$

Based on restriction data it was deduced that $\mathrm{US}_{2}$ consisted of the HindIII fragment
$\mathrm{D}$ into which part of the inverted repeats extended (Fig. 1). Conclusive evidence for this was derived from electron microscopic examination of pDB201-a recombinant plasmid consisting of the cryptic $S$. mutans plasmid pVA318, which has a single HindIII site, and the inserted pSM19035 HindIII fragment $D$ which carried the resistance functions (Behnke and Ferretti, 1980b). Self-annealed pDB201 molecules showed a short double-stranded region ( $\sim 240$ base pairs) and two single-stranded loops (Fig. 2D), the smaller of which was identical in size with $\mathrm{US}_{2}$ of pSM19035 and its derivatives (Table 2). The larger loop corresponded to the molecular length of pVA318 $(5.4 \mathrm{~kb})$ (Macrina and Scott, 1978). No stemloop structures were observed when denatured pVA318 molecules were allowed to self-anneal (data not shown). Therefore, the small loop (resembling $\mathrm{US}_{2}$ ) together with the short double-stranded region of $\sim 240$ base pairs found with pDB201 originated from the cloned HindIII fragment D-the location of the resistance determinant of pSM19035 and its derivatives.

\section{Mapping of the Deletion Termini in pDB101, pDB102, and pDB103}

Mapping of the deletion termini was accomplished by combining $H$ indIII restriction data with results obtained from electron microscopic examination of self-annealed plasmid molecules. To facilitate comprehension, Table 3 and Fig. 3 give a compilation of the data and an example of the logic on which the location of the deletion termini was based. Plasmids pDB101, pDB102, and pDB103 contained the new HindIII fragments $X_{1}, X_{2}$, and $X_{3}$ that were fusion products of the nondeleted remainders of those two fragments in which the deletions terminated (Figs. 1 and 3). Since all of the deletions include part of at least one of the inverted repeats, this fusion point can be located by determining the length of that portion of the $X$ fragment that contains repeated sequences. In the case of $\mathrm{pDB} 101$ (see Fig. 3), this portion should anneal with 
TABLE 3

Compilation of the Data Used to Locate the Deletion Termini of $\Delta 101, \Delta 102$, and $\Delta 103^{a}$

\begin{tabular}{llllll}
\hline Plasmid & $\begin{array}{c}\text { Deleted HindIII } \\
\text { fragments }\end{array}$ & $\begin{array}{c}\text { Unique HindIII } \\
\text { fragments }\end{array}$ & $\begin{array}{c}\text { Molecular } \\
\text { length of the } \\
\text { unique HindIII } \\
\text { fragments } \\
\text { (A) }\end{array}$ & $\begin{array}{c}\text { Length of US } S_{1} \\
\text { as determined } \\
\text { by electron } \\
\text { microscopy } \\
\text { (B) }\end{array}$ & $\begin{array}{c}\text { Extension of the } \\
\text { inverted repeats } \\
\text { into X fragments }\end{array}$ \\
\hline pDB101 & $\left(\mathrm{X}_{0}\right), \mathrm{G}^{\prime},\left(\mathrm{F}^{\prime}\right)$ & $\mathrm{F}, \mathrm{G}, \mathrm{X}_{1}, \mathrm{D}$ & 4810 & 3050 & $880\left(\mathrm{~F}^{\prime}\right.$ or $\left.\mathrm{F}^{\prime}\right)$ \\
pDB102 & $(\mathrm{G}), \mathrm{X}_{0},\left(\mathrm{G}^{\prime}\right)$ & $\mathrm{X}_{2}, \mathrm{D}$ & 680 & - & $340\left(\mathrm{G}, \mathrm{G}^{\prime}\right)$ \\
pDB103 & $\left(\mathrm{X}_{0}\right), \mathrm{G}^{\prime}, \mathrm{F}^{\prime},\left(\mathrm{B}^{\prime}\right)$ & $\mathrm{B}, \mathrm{F}, \mathrm{G}, \mathrm{X}_{3}, \mathrm{D}$ & 7140 & 6320 & $410\left(\mathrm{~B}\right.$ or $\left.\mathrm{B}^{\prime}\right)$ \\
\hline
\end{tabular}

a All molecular lengths are given as nucleotides or nucleotide pairs (bp).

${ }^{b}$ The fragments indicated formed the deletions $\Delta 101, \Delta 102$, and $\Delta 103$ yielding plasmids pDB101, pDB 102 , and $\mathrm{pDB} 103$, respectively. The nondeleted remainders of the termination fragments (indicated by parenthesis) fused to the HindIII fragments $\mathrm{X}_{1}, \mathrm{X}_{2}$, and $\mathrm{X}_{3}$.

${ }^{c}$ These values do not include the unique fragment $D$ since it has been shown to form the unique sequence $\mathrm{US}_{2}$. All molecular lengths were calculated from restriction data (Behnke et al., 1979b; Behnke and Ferretti, 1980a).

${ }^{d}$ The extentions of the inverted repeats into the $\mathrm{X}$ fragments are identical with the nondeleted remainder of one of the termination fragments (the particular fragment is given in parcnthesis), thus, yielding their fusion point which allows the location of the map positions of the deletion termini in the original HindIII fragments.

an equivalent portion of fragment $F$. The length of this annealed portion corresponds to one-half of the difference between the sum of the unique HindIII fragments (ignoring fragment D) and the length of $U S_{1}$ determined by electron microscopy (Table 3). In this manner the fusion points were located, and the map positions of the deletion-termini on the original HindIII fragments were calculated from the length of their nondeleted residues contributing to the $\mathrm{X}$ fragments.

Detailed map positions for $\Delta 101, \Delta 102$, and $\Delta 103$ are shown in Fig. 4. One deletion

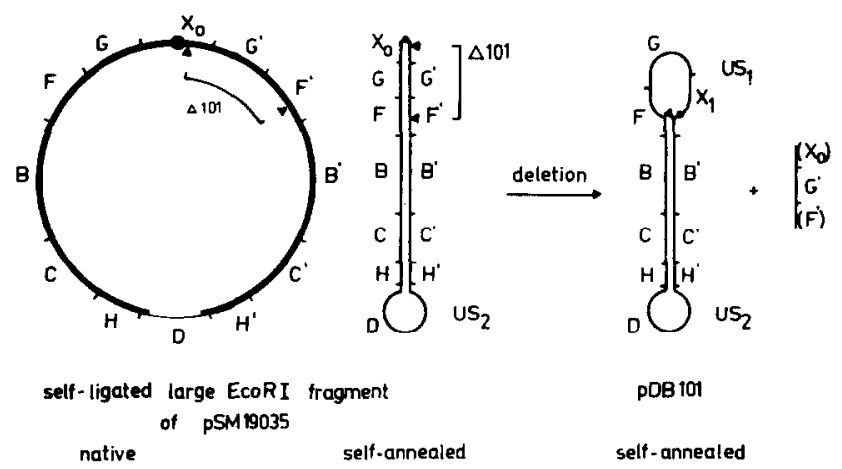

FIG. 3. Example of the logic on which the localization of deletion termini was based. HindIII fragment $\mathrm{X}_{1}$ was the fusion product of the nondeleted remainders of those HindIII fragments where $\Delta 101$ terminated. One of these residues (belonging to $F^{\prime}$ ) formed the extension of the inverted repeat of pDB101 into fragment $X_{1}$ and could, therefore, be determined as half of the difference between the total length of fragments $F, G$, and $X_{1}$ (covering $U S_{1}$ ) and the actual size of $U S_{1}$. The position of the fusion point then allowed determination of the map positions of the deletion termini on the original HindIII fragments. Solid circles indicate EcoRI cleavage sites and arrows point to the deletion termini. The heavy line in the native ligated $E c o$ RI fragment represents inverted repeats and the light line the interstitial sequence. 


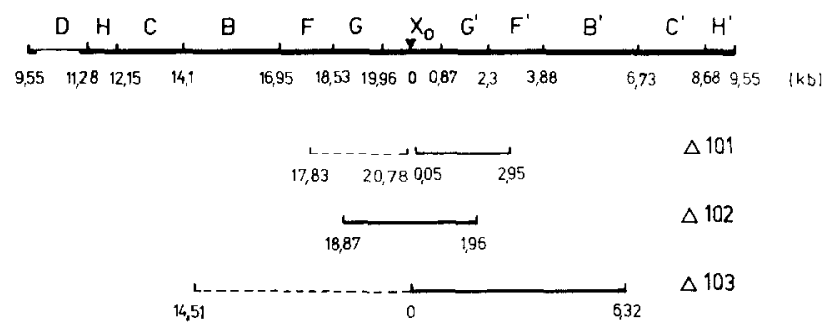

FIG. 4. Map locations of the deletions $\Delta 101, \Delta 102$, and $\Delta 103$ in relation to HindIII cleavage sites on the map of the linear large EcoRI fragment of pSM19035. The single EcoRI cleavage site (arrow) represents the junction point between the two inverted repeats (heavy lines). Two locations are possible for deletions 101 and 103 (solid or dotted lines) because of the internal symmetry of the molecule.

terminus of $\Delta 101$ was located $\sim 50$ base pairs away from the single EcoRI site leaving it unaffected. In contrast, $\Delta 103$ removed the single EcoRI site; thus, the deletion extended beyond this point. This $\triangle 103$ endpoint has been mapped close to the EcoRI site and it would appear to be in a similar position as the $\Delta 101$ terminus only on the opposite side of the EcoRI site. No real significance can be assigned to the $\sim 50$ base pair deviation of the positions of these two deletion termini, since the method used to calculate their locations does not yield such resolution. Deletion $\Delta 102$ extended into both repeats appearing to have symmetrically located end points.

\section{DISCUSSION}

Introduction of the self-ligated large EcoRI fragment of pSM19035 into Challis by transformation is accompanied by deletions of DNA segments from its extraordinarily long inverted repeats. These repeats cover about $92 \%$ of the total molecule (Behnke et al., 1979b). Analyses of single-stranded loops and double-stranded regions in selfannealed molecules of plasmids pDB101, pDB 102, and pDB 103 (Figs. 2A-C; Table 2) established the location and the extent of the deletions. Mapping of the deletion termini suggests the interesting possibility that preferential sites may be located on the HindIII fragments $G$ or $G^{\prime}$ and $X_{0}$. One terminus of the deletions $\Delta 101$ and $\Delta 103$ was localized close to, although on different sides of, the single EcoRI site. It is conceiv- able that these sites are identical distances from the EcoRI site and represent identical points in the two inverted repeats. Deletion $\Delta 102$ extended into both of the inverted repeats with apparently symmetrical endpoints on the sister HindIII fragments G and $\mathrm{G}^{\prime}$. The possible presence of preferential sites for deletion termini could reflect hot spots for internal recombinational events. However, as reciprocal recombination between symmetrical sites in a pair of inverted repeat sequences will result in inversion and not deletion of the intervening segment, it is difficult to account for $\Delta 102$ on this basis.

Electron microscopic analysis of a recombinant plasmid consisting of the small cryptic plasmid pVA318 (Macrina and Scott, 1978) and the unique HindIII fragment D cloned from pDB102 (Behnke and Ferretti, 1980b) showed that the latter fragment gives rise to the unique sequence $\mathrm{US}_{2}$. This fragment contains the MLS resistance determinant and is present in all three of the deleted plasmids, as well as the original pSM19035.

Insofar as the $\mathrm{US}_{2}$ sequence $(1.4 \mathrm{~kb})$ is relatively small (room for only one or a few genes), it probably contains genetic information related only to MLS resistance. This brings up the very interesting question regarding the location of genes related to replication. Since the remainder of the pDB101, pDB102, and pDB103 molecules consists of sequences that are repeated in pSM19035, the replication functions must be located on these sequences. Thus, all 
replication genes must be present in duplicate and arranged in reverse orientation with respect to each other. It also follows that there are probably two origins of replication. Two replication origins have been reported in the case of the R6K (Crosa et al., 1975; Lovett et al., 1975) and NR1 (Perlman and Rownd, 1976). There is no evidence, however, for the involvement of extensive duplicate segments of origincontaining DNA in these plasmids. Analyses of the replication of pSM19035 should yield information on whether two origins are in fact used, and whether replication from the origin(s) is unidirectional or bidirectional. Analysis of replication might also shed some light on why pSM19035 stably maintains such extraordinarily long duplicate sequences.

\section{ACKNOWLEDGMENTS}

We wish to thank Dr. J. Ferretti for his help in supporting certain aspects of this study. Support also was provided by Public Health Research Grant DEO2731 from the National Institute of Dental Research Grants AI10318 and K04 AI00061 (Research Career Development Award to DBC) from the National Institute of Allergy and Infectious Diseases.

\section{REFERENCES}

Behnke, D., Golubkov, V. I., Malke, H., Boitsov, A. S., And Totolian, A. A. (1979a). Restriction enzyme analysis of group A streptococcal plasmids determining resistance to macrolides, lincosamides and streptogramin-B antibiotics. FEMS Microbiol. Lett 6, 5-9.

Behnke, D., Malke, H., Hartmann, M., and Walter, F. (1979b). Post-transformational rearrangement of an in vitro reconstructed group $A$ streptococcal erythromycin resistance plasmid. Plasmid 2, 605-616.

Behnke, D., And Ferretti, J. J. (1980a). Physical mapping of plasmid pDB101: a potential vector plasmid for molecular cloning in streptococci. Plasmid 2, 130-138.
Behnke, D., ANd Ferrett,, J. J. (1980b). Molecular cloning of an erythromycin resistance determinant in streptococci. J. Bacteriol, in press.

Boitsov, A. S., Golubkov, V. I., Iontova, I. M., Zaitsev, E. N., Malke, H., and Totolian, A. A. (1979). Inverted repeats on plasmids determining resistance to MLS antibiotics in group A streptococci. FEMS Microbiol. Lett. 6, 11-14.

Chassy, B. M. (1976). A gentle method for the lysis of oral streptococci. Biochem. Biophys. Res. Commun. 68, 603-608.

Crosa, J. H., Luttropp, L. K., HefFron, F., AND FALkow, S. (1975). Two replication initiation sites on R plasmid DNA. Mol. Gen. Genet. 140, 39-50.

Davis, R. W., Simon, M., ANd Davidson, N. (1971). In "Methods in Enzymology" (L. G. Grossman, and K. Moldave, eds.), Vol. 21D, pp. 413-428. Academic Press, New York.

Lovett, M. A., Sparks, R. B., ANd Helinski, D. R. (1975). Bidirectional replication of plasmid $R 6 \mathrm{~K}$ DNA in Escherichia coli. Correspondence between origin of replication and position of single-strand break in relaxed complex. Proc. Nat. Acad. Sci. USA 72, 2905-2909.

Macrina, F. L., ANd Scott, C. L. (1978). Evidence for a disseminated plasmid in Streptococcus mutans. Infect. Immunol. 20, 296-302.

MALKE, H. (1974). Genetics of resistance to macrolide antibiotics and lincomycin in natural isolates of Streptococcus pyogenes. Mol. Gen. Genet. 135, 349-367.

Perlman, D., And Rownd, R. H. (1976). Two origins of replication in composite $R$ plasmid DNA. Nature (London) 259, 281-284.

Reider, J. L., AND Macrina, F. L. (1976). Plasmid DNA isolation in $S$. mutans: glycine enhanced cell lysis. Spec. Suppl. Microbiol. Abstr. 3, 725-736.

Sanger, F., Air, G. M., Barrell, B. G., Brown, N. L., Coulson, A. R., Fielder, J. C., HutchiSon, C. A., III, Slocombe, P. M., ANd Smith, M. (1977). Nucleotide sequence of bacteriophage $\phi \mathrm{X}$ 174 DNA. Nature (London) 265, 681-695.

Sharp, Z. A., Hsu, M., Ohtsubo, E., ANd Davidson, N. (1972). Electron microscope heteroduplex studies of sequence relations among plasmids of Escherichia coli. I. Structure of F prime factors. J. Mol. Biol. 71, 471-497.

YaGi, Y., AND Clewell, D. B. (1976). Plasmiddetermined tetracycline resistance in Streptococcus faecalis: tandemly repeated resistance determinants in amplified forms of pAM $\alpha 1$ DNA. J. Mol. Biol. $102,583-600$. 